\title{
Occupational Risk Identification Using Hand-Held or Laptop Computers
}

\author{
Paula Naumanen \\ Finnish Institute of Occupational Health, Kuopio, Finland
}

Heikki Savolainen

Department of Occupational Safety and Health, Ministry of Social Affairs and Health, Tampere, Finland

\section{Jyrki Liesivuori}

\section{Finnish Institute of Occupational Health, Turku, Finland}

This paper describes the Work Environment Profile (WEP) program and its use in risk identification by computer. It is installed into a hand-held computer or a laptop to be used in risk identification during work site visits. A 5-category system is used to describe the identified risks in 7 groups, i.e., accidents, biological and physical hazards, ergonomic and psychosocial load, chemicals, and information technology hazards. Each group contains several qualifying factors. These 5 categories are colour-coded at this stage to aid with visualization. Risk identification produces visual summary images the interpretation of which is facilitated by colours. The WEP program is a tool for risk assessment which is easy to learn and to use both by experts and nonprofessionals. It is especially well adapted to be used both in small and in larger enterprises. Considerable time is saved as no paper notes are needed.

risk identification assessment work site visit hand-held computer laptop print-outs

\section{INTRODUCTION}

A comprehensive and transparent risk assessment procedure is the key to managing and lessening the dangers to health and safety at European workplaces. Many existing risk assessment procedures are time consuming since they generate large amounts of paperwork which is not easily mastered by the users $[1,2]$. One workplace visit may require the time investment of up to $4 \mathrm{hrs}$ by occupational health professionals. Of this time, 2 hrs may be spent on risk identification and assessment, $11 / 2 \mathrm{hrs}$ on reporting, and one hour on providing feedback to the enterprises
[3]. In addition, occupational health professionals consider chemicals and psychosocial factors to be the most difficult to assess [2]. Thus, there is a clear need to develop a system which would allow a more efficient way of collecting data, e.g., during a single walk-through survey.

Therefore, experts in the Finnish Institute of Occupational Health have developed a new risk assessment method called the Work Environment Profile (WEP) program, which can be operated either with a hand-held computer or a laptop. It is the first electronic risk assessment method applied in Finland for a computer that runs the newest Windows operating system. The variables of the

Correspondence and requests for offprints should be sent to Paula Naumanen, Finnish Institute of Occupational Health, P.O. Box 93, FI-70701 Kuopio, Finland. E-mail: <paula.naumanen@ttl.fi>. 
program were developed on the basis of the latest surveys on health hazards and safety legislation in Finland, in co-operation with occupational health and safety professionals and by applying the British Standard 8800 principles [4]. The system covers all of the most general work environment health hazards. This paper describes the WEP program and its use in risk assessment with some examples from companies.

The use of a hand-held computer has been described in many applications. The device has been successfully used by health professionals when documenting patient data and using printed data in decision making $[5,6,7]$, telementoring surgical procedures [8], securing patients' identity at blood sampling and transfusion procedures [9], following patients' blood glucose level [10], measuring rapidly and easily blood pressure, pulse rate, temperature, and oxygen saturation via health monitoring sensors connected to the handheld computer [11], and in counselling patients about their symptoms [12]. Hand-held computers have also been used to document clinical and educational activities and in medical student education, daily training, clinical practice and research $[13,14,15]$. Clinical study participants have also answered questions concerning their health status and health risk behaviours by using hand-held computers in laboratories and workplaces without compromising the confidentiality of their data $[16,17,18,19]$.
The automatic recording of measurements is very common in occupational hygiene, where signals are often introduced directly into a data logger or a computer. Monitoring threshold concentrations of chemicals, e.g., in workplace air, with a computer-assisted system with relevant sensors is a typical automatic surveillance technique [20]. A computer tool has been designed to perform rapid calculation of the so-called risk severity indexes for thermal radiation, toxic concentration and overpressure together with the probabilities and frequencies associated with critical events and their consequences [21]. One computerized handheld occupational risk assessment procedure with a hazard listing and semiquantitative risk assessment scales utilizes the Pendragon Forms software version 3.2 and Access format [22].

\section{METHOD}

\subsection{The WEP Program}

The WEP program includes all general health and safety hazards grouped into accidents; physical and mental load; chemical, biological and physical factors; and data systems and computer program displays (Table 1). Each group is formed from several individual factors, with the criteria for classifications, and the risk assessment system being categorized with colours.

\section{TABLE 1. Modules With Variables of the Work Environment Profile (WEP) Program}

\section{Chemicals, Wood Dust, Stone Dust, Fibres and Other Air Impurities}

1 Listing of each chemical separately $(\leq 50)$

\section{Biological Factors}

1 High humidity and bad quality of air

2 Dust

3 Dirty process liquids and aerosols

4 Bacteria, viruses and fungi in human and animal samples

5 Other biological factors

\section{Physical Factors}

1 Noise

2 Vibration

3 Radiation

4 Poor lightning or too bright

5 Heat or coldness 
TABLE 1. (continued)

\begin{tabular}{|c|c|}
\hline & Accidents \\
\hline 1 & Slipping or stumbling \\
\hline 2 & Falling down \\
\hline 3 & Getting run over by vehicle or machine \\
\hline 4 & Inserting body parts into machine or instrument \\
\hline 5 & Falling or splashing of compounds, articles or liquids \\
\hline 6 & Wounds \\
\hline 7 & Fire, burns or explosions \\
\hline 8 & Electric shocks \\
\hline 9 & Fatal drowning accident, asphyxiation or being trapped \\
\hline 10 & Inadequate first aid and rescue equipment and routes \\
\hline 11 & Inadequate first aid skills \\
\hline \multirow[t]{2}{*}{12} & Other dangerous situations \\
\hline & Physical Load \\
\hline 1 & Handling heavy load repeatedly \\
\hline 2 & Non-ergonomic work posture repeatedly \\
\hline 3 & Heavy physical movements \\
\hline 4 & Continuous sitting or standing \\
\hline 5 & Similar and repeated movements of hands \\
\hline 6 & Defective and difficult machines, instruments and programmes \\
\hline 7 & Non-ergonomic dimensioned and adjusted worktop and chairs \\
\hline 8 & Non-ergonomic location of display unit, keyboard or mouse \\
\hline 9 & Inadequate knowledge of ergonomics \\
\hline \multirow[t]{2}{*}{10} & Other ergonomic factors \\
\hline & Mental Load \\
\hline 1 & Irregular working hours or continuous overtime work \\
\hline 2 & Too much or too few work tasks \\
\hline 3 & Excessive work and being on the alert continuously \\
\hline 4 & Too difficult or too easy tasks compared to personal skills \\
\hline 5 & Working continuously alone without companionship possibilities \\
\hline 6 & Unclear division of labour and responsibilities \\
\hline 7 & Informing problems \\
\hline 8 & Low influence possibilities \\
\hline 9 & Workplace violence, sexual harassment or mistreatment \\
\hline 10 & Problems in co-operation \\
\hline \multirow[t]{2}{*}{11} & Other mental load factors \\
\hline & Information Technology Problems \\
\hline 1 & Too small letters and graphical elements \\
\hline 2 & Low colour or light contrast \\
\hline 3 & Confusing connecting point \\
\hline 4 & Difficulties in observing important changes in user interface \\
\hline 5 & Wrong or unreliable information in user interface \\
\hline 6 & Illogical or unsystematic items on user interface \\
\hline 7 & Difficulties in making revisions \\
\hline 8 & Difficulties with instructions or system does not offer help or advice \\
\hline 9 & Other difficulties in using information systems and programmes \\
\hline
\end{tabular}


The program includes a list of 47 most common work environmental health hazards. In addition, there is space to include missing health hazards at the end of each module, and also a possibility to list 50 chemicals.

The WEP program was tested in 43 smallscale enterprises, in 14 occupational health care units, in 24 large factories and in 6 municipal workplaces conducted by them and a researcher. Branches ranged from health care to forestry and metal working firms containing many different kinds of risk domains. The WEP program was validated and the agreement for the whole program was $68.3 \%$, which situated it on the good level (scale: very bad $<20 \%$, bad $21-40 \%$, moderate 41-60\%, good 61-80\%, very good 81$100 \%)$.

The use of the program requires a laptop Windows operating system with the newest operating systems (Windows 2000, Me or XP versions, and Excel version 2000 or 2003). The

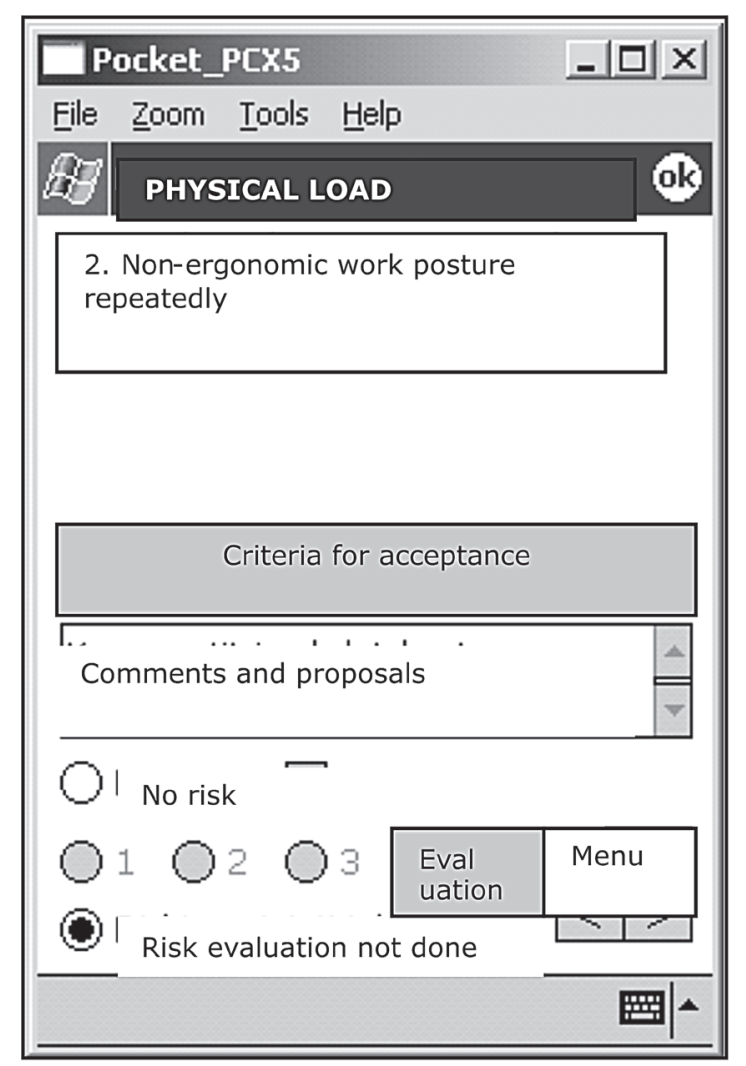

Figure 1. A sample view of a factor. Clicking on "Criteria for acceptance" opens the view in Figure 2. If there is risk, clicking on "Evaluation" opens Figures 3 and 4. prerequisites for the hand-held computer are Windows operating systems such as Pocket PC 2002, Windows Mobile 2003 or 2003 Second Edition and Windows Mobile 5.0. Basic information technology skills and information technology support in the organization are essential requirements when starting to operate the WEP program.

\subsection{Risk Assessment Process}

The risk assessment process starts with identifying the workers' main tasks, the time needed for these tasks and exposure to health hazards. This information helps in assessing the risk these factors cause. Each of them is assessed with individual criteria for acceptance (Figure 1), which can be visualized when clicking the relevant icon (Figure 2). If there is no risk or everything is in order, this is marked by clicking "no risk". This can be seen as marked 0 in

\begin{tabular}{l}
\hline Porket_PCX5 \\
File zoom Iools Help \\
My PHYSICAL LOAD \\
Maximum 2 hours/day can be \\
allowed to work so that the neck or \\
back is bent or twisted (over $30^{\circ}$ ), \\
arms are in the overhead position, \\
elbows are above shoulder level or \\
the individual needs to sit on \\
his/her legs, haunches or knees. It \\
is important to be able to take \\
breaks when the individual feels \\
they are necessary. \\
\end{tabular}

Figure 2. A sample view when "Criteria for acceptance" is clicked on. 
Figure 5. Then, one can move to assess the risk of the next factor.

If the qualifying criteria for acceptance are not met, health may be at risk; therefore, risk assessment has to be carried out by using a coloured risk assessment system which is opened by clicking the Evaluation panel (Figure 1). Initially, exposure frequency or probability (seldom, sometimes, often; improbable, possible, probable) is evaluated and this is kept in mind (Figure 3). Then, the level of exposure or the consequences (slight, harmful, serious) are evaluated (Figure 4). More detailed information about each exposure frequency and hazard groups is presented in the box below when clicking on each level. The hazard groups include information concerning health symptoms, length of sickness absences, limit values, and certain Risk Phrases depending on the factor. The risk level is determined by the exposure frequency and gravity of the hazard.

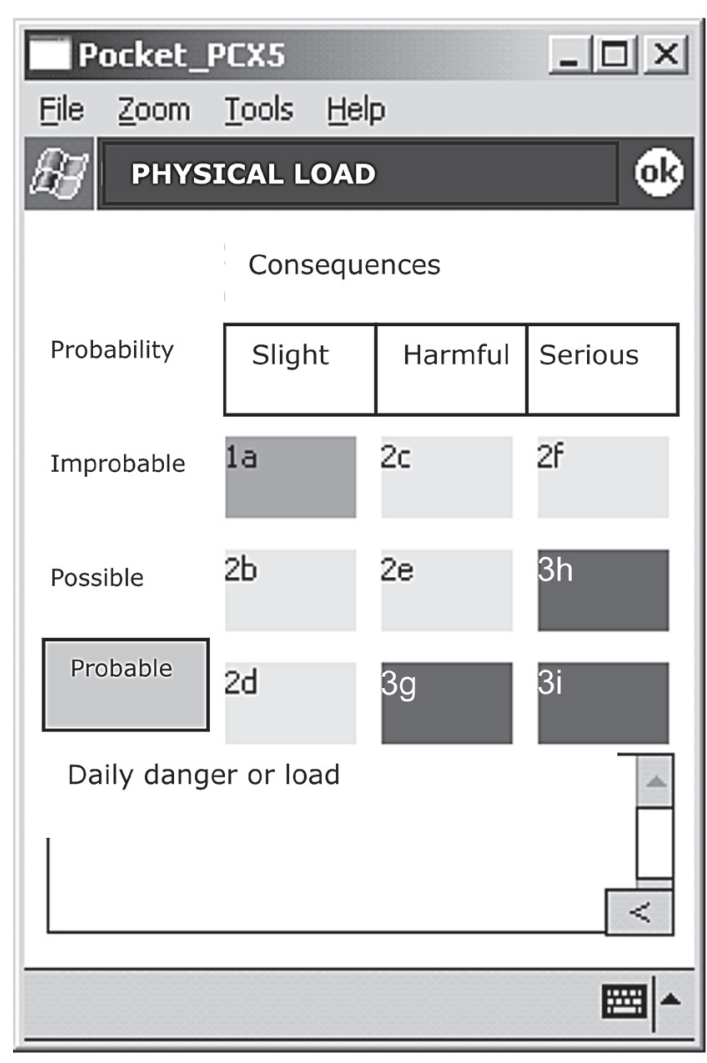

Figure 3. An explanation of exposure when "Probable" is clicked on.
If the factor is assessed as minor (marked 1 in Figure 5), the existing risk for health is minor and it may be unnecessary to eliminate it. The second category ( 2 in Figure 5) means risk to health is moderate and needs to be managed better. The third category ( 3 in Figure 5) denotes a definitive risk for health and need for urgent measure. Risk assessment will be marked 4, if it has been omitted. There is also space for comments and recommendations to help with planning and decisions on the development measures to be taken in the workplace (Figure 1). Comments are seen afterwards in the follow-up form (Figure 6). The collated risk assessments can be transferred from a hand-held computer to a laptop via a cable or wireless communication technology for subsequent analysis. One can avoid data transferring if the WEP program is used on a laptop. Data can be completed and revised afterwards if necessary. Once all of the pertinent

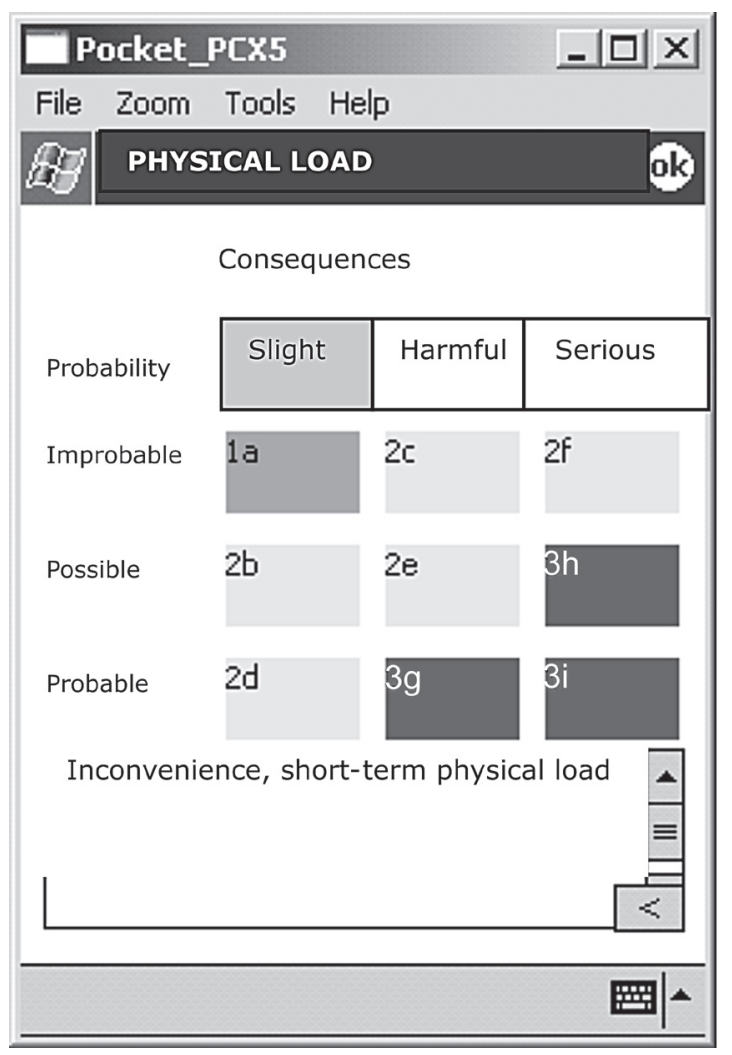

Figure 4. An explanation of exposure when "Slight" is clicked on. 
data are saved, the results can be analysed very quickly with an analytical program adapted for Microsoft Office Excel 2002 or 2003. If average reporting time takes $1.2 \mathrm{hrs}$ when typing notes on paper [3], it takes only a few seconds when analysing the data saved with the WEP program.

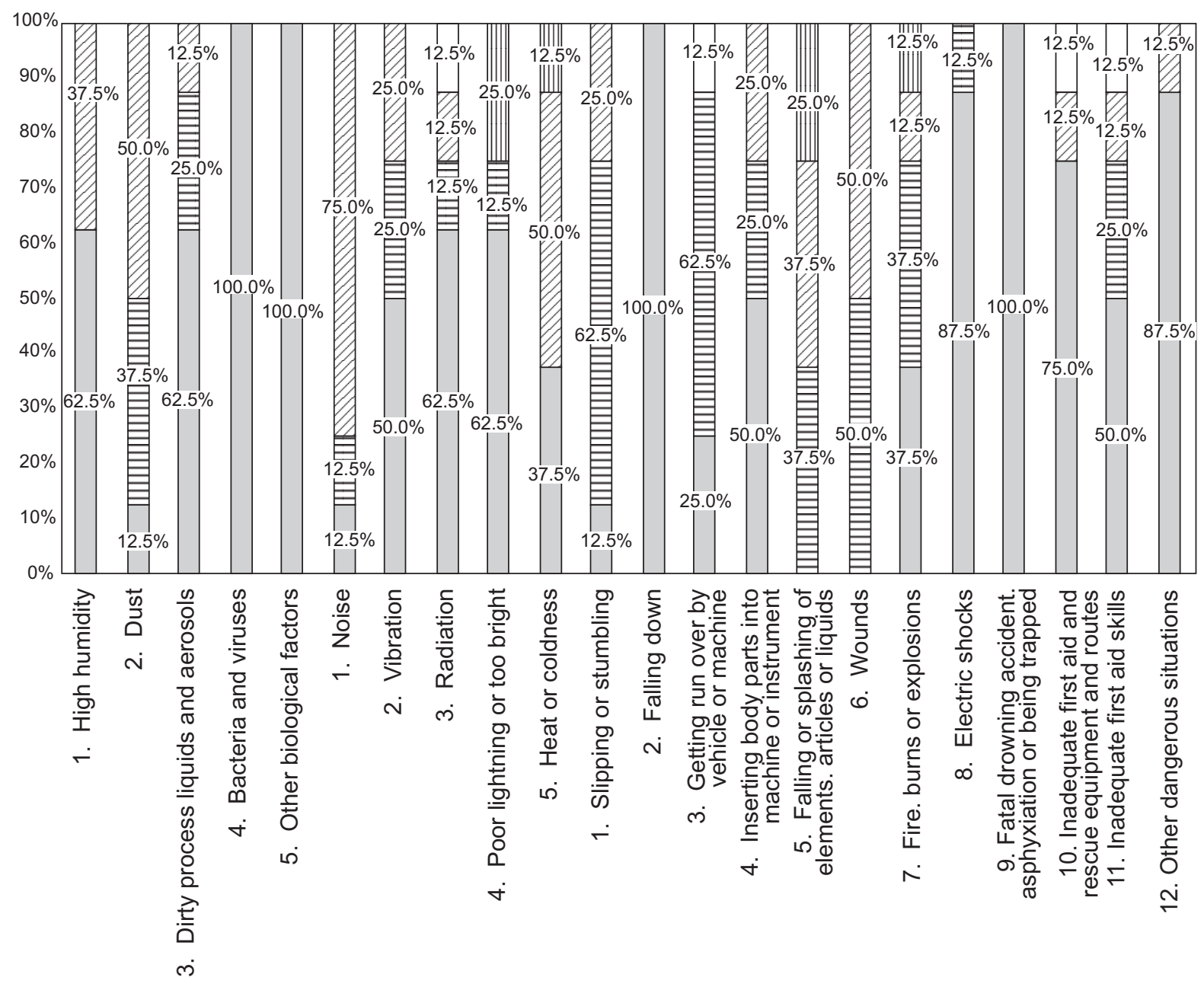

$\square 4$ risk assessment not done

玍 3 high risk, improvements obligatory

$\square 2$ moderate risk, improvements to be considered

Е 1 small risk, improvements are not necessary

0 no risk, things are in order

Figure 5. Sample results of biological and physical factors and accidents according to combined risk assessment in 20 small-scale enterprises representing the metal branch. 


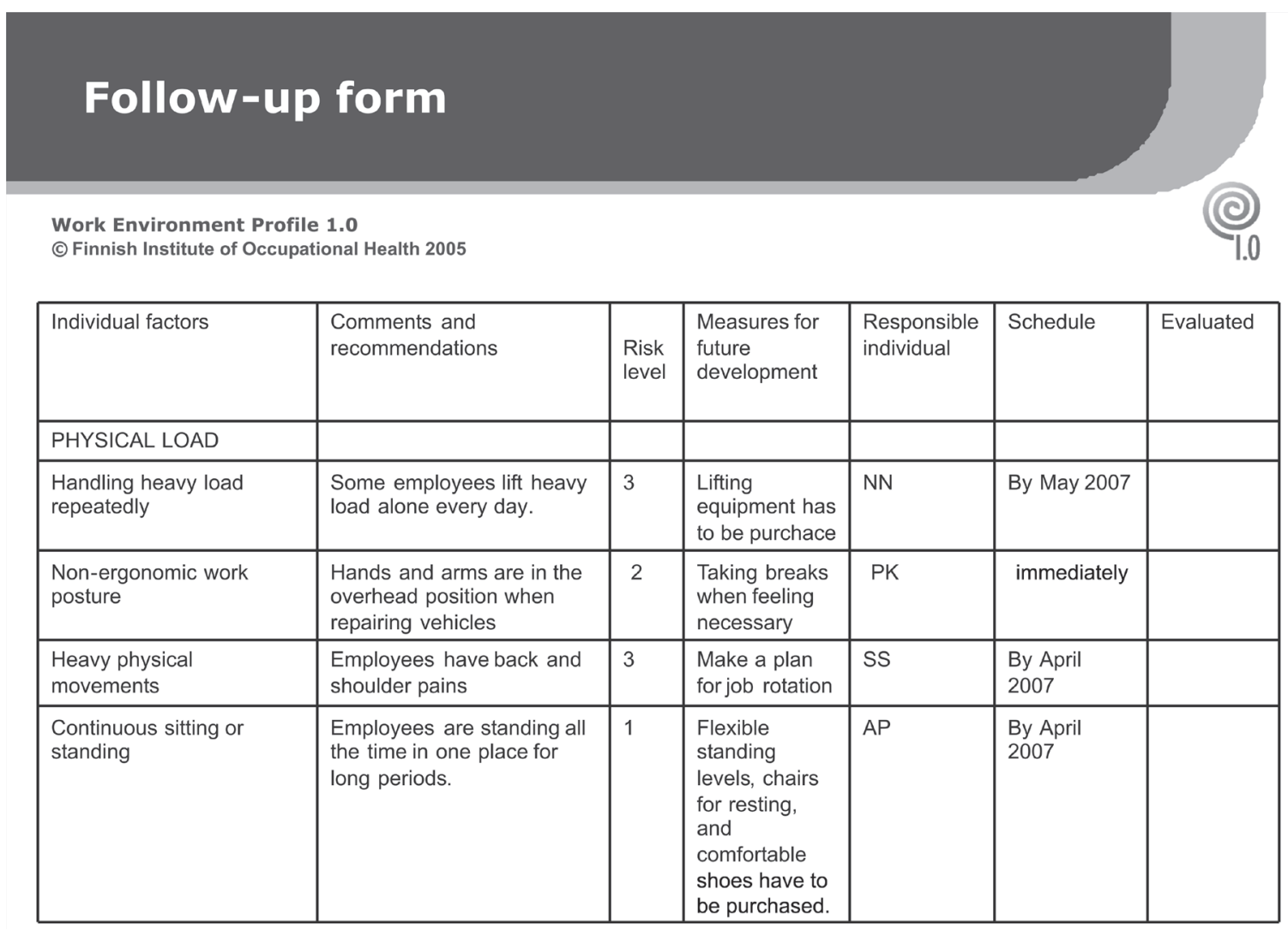

Figure 6. Sample factors, comments, measures for future development, the responsible individual and the schedule linked to them in a follow-up form.

\section{RESULTS}

The findings of risk assessment are visualized in summary print-outs: bar charts of the health and safety risks and follow-up forms. The magnitude of each risk can be assessed by examining the range of patterns representing numbers 1-4 on the bar charts (Figure 5). Several risk assessment results can be combined in the same analysis to evaluate the general situation considering the level of risk posed by individual factors in the entire company. As an example, Figure 5 shows some combined risk assessment results of biological and physical factors and accidents in 20 small-scale enterprises representing the metal branch. According to the results, the highest and moderate risk was caused by poor light and thermal conditions, noise, dust, high humidity, and accidents (wounds, burns, falling elements). Other identified moderate risk (not shown in the figure) was caused by chemicals, poor use of personal protective equipment as well as by physical and mental load [23].

The follow-up form presents explanatory remarks for the risk levels (and numbers) (Figure 6). It also includes comments and recommendations, suggestions for further refinement, responsibilities and time schedules for undertaking health and safety actions. The followup form is meant to be used after risk assessment as a tool when improvement procedures are introduced. It should be possible to visualize how working conditions have improved.

\section{CONCLUSION}

The WEP program is useful for occupational health professionals and health and safety officers with limited resources and time at their disposal, because the data are collected and saved at once and the analysis process is quick and convenient [12]. Thus, the WEP program minimizes 
paperwork and makes a comparison between past, current and future risk assessment possible. It also allows occupational health professionals to offer a new service to enterprises and to co-operate with them on the development of working conditions. The WEP program provides an option to use only one suitable document for all representatives as required by Council Directive 89/391/EEC [24]. It may even increase the collaboration of different experts and nonprofessionals at the level of the workplace. If several people and apparatuses are used simultaneously the risk of errors and omissions in risk identification may be minimized even further.

By utilizing information technology, the WEP program helps to identify and to assess the most common health hazards and defects at workplaces. Now it is also available in English. Translation into other languages is also possible as the program uses the conventional terminology of occupational safety and health. Future versions of the program will include more specific possibilities for risk management.

\section{REFERENCES}

1. Murtonen M. Risk assessment in workplace. Tampere, Finland: Department of Occupational Safety and Health, Ministry of Social Affairs and Health, Tampere; 2003. In Finnish.

2. Vainio $\mathrm{H}$, Liesivuori J, Lehtola $\mathrm{M}$, Louekari K, Engström K, Kauppinen T, et al. Chemicals and work. Report from chemical risks of work environment. Helsinki, Finland: Finnish Institute of Occupational Health; 2005. In Finnish.

3. Naumanen P, Liesivuori J. Work activity analysis of Finnish occupational health professionals. Occup Med. 2007:57(2):141-144. Retrieved September 21, 2007, from: http:// occmed .oxfordjournals.org/cgi/reprint/kq11 08v1 ?ijkey $=$ Wn351Jp21UEclsE\&keytype $=$ ref (DOI:10.1093/occmed/kql108).

4. British Standards Institution. Guide to occupational health and safety management systems (Standard No. BS 8800). Helsinki, Finland: SFS; 1996. In Finnish.
5. Koop A, Mösges R. The use of handheld computers in clinical trials. Control Clin Trials. 2002;23:469-80.

6. Oyama L, Tannas HS, Moultin S. Desktop and mobile software development for surgical practice. J Pediatr Surg. 2002; 37(3):477-81.

7. France DJ, Miles P, Cartwright J, Patel N, Ford C, Edens C, et al. A chemotherapy incident reporting and improvement system. Jt Comm J Qual Saf. 2003;29(4):171-80.

8. Gandsas A, McIntire K, Montgomery K, Bumgardner C, Rice L. The personal digital assistant (PDA) as a tool for telementoring endoscopic procedures. Stud Health Technol Inform. 2004;98:99-103.

9. Chan JC, Chu RW, Young BW, Chan F, Chow CC, Pang WC, et al. Use of an electronic barcode system for patient identification during blood transfusion: 3-year experience in a regional hospital. Hong Kong Med J. 2004;10(3):166-71.

10. Broers S, van Vliet KP, le Cessie S, Spinhoven P, van der Ven NC, Radder JK. Blood glucose awareness training in Dutch type 1 diabetes patients: one-year followup. Neth J Med. 2005;63(5):164-9.

11. Sachpazidis I, Stassinakis A, Memos D, Fragou S, Nachamoulis S, Vamvatsikos A, et al. @HOME is a new EU-Project in Tele Home care. Biomed Tech (Berl). 2002;47(Suppl 1 Pt 2):970-2. In German, with an abstract in English.

12. Lee HR, Yoo SK, Jung SM, Kwon NY, Hong CS. A web-based mobile asthma management system. J Telemed Telecare. 2005;11(Suppl 1):56-9.

13. Malter D, Davis T. Data collection and "real-time" learning using handheld computers. Appl Occup Env Hyg. 2003;18: 321-30.

14. Baumgart DC. Personal digital assistants in health care: experienced clinicians in the palm of your hand? Lancet. 2005;366 (9492):1210-22.

15. MacGregor DL, Tallett S, MacMillan S, Gerber R, O'Brodovich H. Clinical and education workload measurements using personal digital assistant-based software. Pediatrics. 2006;118(4):e985-91. Retrieved September 21, 2007, from: http:// 
pediatrics.aappublications.org/cgi/content/ abstract/118/4/e985 (DOI:10.1542/peds.20060515).

16. Härmä M, Hakola $T$, Kandolin $I$, Sallinen M, Virkkala J, Bonnefond A. A controlled intervention study of a quickly forward rotating shift system among young and elderly maintenance workers. In: Program and Abstracts. XVI International Symposium on Night and Shiftwork. Equity and working time: a challenge to be achieved. Shiftwork International Newsletter. 2003;2:86.

17. Bobula JA, Anderson LS, Riesch SK, Canty-Mitchell J, Duncan A, KaiserKrueger HA, et al. Enhancing survey data collection among youth and adults: use of handheld and laptop computers. Comput Inform Nurs. 2004;22(5):225-65.

18. van Griensven F, Naorat S, Kilmarx PH, Jeeyapant S, Manopaiboon C, Chaikummao S. et al. Palmtop-assisted self-interviewing for the collection of sensitive behavioral data: randomized trial with drug use urine testing. Am J Epidemiol. 2005;163(3): 271-8.

19. Riley WT, Carson SC, Martin N, Behar A, Forman-Hoffman VL, Jerome A. Initial feasibility of a researcher configurable computerized self-monitoring system. Comput Human Behav. 2005;21(6):1005-18.

20. Pośniak M, Skowroń J. Polish system of assessing occupational risk posed by chemical compounds. International Journal of Occupational Safety and Ergonomics (JOSE). 2000;Spec No:103-9.

21. Planas E, Arnaldos J, Silvetti B, Vallee A, Casal J. A risk severity index for industrial plants and sites. J Hazard Mater. 2005; 130(3):242-50.

22. Venez D, Poffet JM, Besrour A. Handheld-assisted field data collection for occupational risk assessment. International Journal of Occupational Safety and Ergonomics (JOSE). 2004;10(4):399-410.

23. Naumanen P, Savolainen H, Liesivuori J. Work circumstances in small-scale enterprises in middle and eastern Finland. Work and People. 2006;20(2):117-31. In Finnish, with an abstract in English.

24. Council Directive 89/391/EEC of 12 June 1989 on the introduction of measures to encourage improvements in the safety and health of workers at work. OJ. 1989;L 183: $1-8$. 